\title{
APPLICATION OF DIVERGENT SPLIT INJECTION IN A CIDI DIESEL ENGINE TO REDUCE EMISSIONS AND BOOST THE EFFICIENCY
}

\author{
Hadi TAGHAVIFAR* \\ Dept of Mechanical Engineering, Faculty of Engineering, Malayer University, Iran
}

Received 9 January 2017; revised 26 December 2017; accepted 23 January 2018

\begin{abstract}
The application of single injection in diesel engines has been becoming outdated given the advent of High-Pressure Common Rail (HPCR) system. Multiple injection or split injection presents more controllability over the economic use of fuel during the injection process. In this sense, a thorough investigation of a new concept with the use of divergent injection and split injection is proposed, based on which the whole chamber area was covered with two nozzles of different angles. Moreover, the system allows the optimal use of time span for injection in by assigning different dwell-time periods between injection pulses. The results indicate that increasing the divergence of nozzle angles could possibly bring about arise of Uniformity Index (UI) and Indicated Power (IP) of engine. In contrast, increase of dwell time leads to deterioration of Indicated Mean Effective Pressure (IMEP) and Indicated Specific Fuel Consumption (ISFC). The data points of several injection schemes are presented in IMEP-NO $\mathrm{N}_{\mathrm{x}}$ and ISFC-soot plots in comparison with single injection that shows adoption of a proper injection policy can establish an ideal trade-off between emissions and engine performance.
\end{abstract}

Keywords: diesel engine, divergent injection, emissions, split injection, uniformity index.

\author{
Abbreviations \\ ATDC - after top dead center; \\ BDC - bottom dead center; \\ BTDC - before top dead center; \\ CA - crank angle; \\ CFD - computational fluid dynamics; \\ CIDI - compression-ignition direct-injection \\ DDM - discrete droplet model; \\ DI - direct injection; \\ ECFM - extended coherent flame model; \\ EGR - exhaust gas recirculation; \\ ER - equivalence ratio; \\ FGT - fixed-geometry turbocharging; \\ HPCR - high-pressure common rail; \\ HRR - heat release rate; \\ HSDI - high speed direct injection; \\ IMEP - indicated mean effective pressure; \\ IP - indicated power; \\ ISFC - indicated specific fuel consumption; \\ LTC - limiting torque condition; \\ MCC - microscale combustion calorimeter; \\ $\mathrm{NO}_{\mathrm{x}}$ - nitrogen oxide;
}

SR - swirl ratio;

TDC - top dead center;

UI - uniformity index;

UDF - user defined function;

VGT - variable-geometry turbocharging.

\section{Introduction}

Due to ratification of stringent rules for the exhaust emissions of vehicles (Sands et al. 2018) next to necessity to boost the engine performance, new ideas and designs for the engine have been put forward by the research communities. Advanced injection systems require high-injection pressure complex called common rail where there is flexibility by electronic devices to control the amount of fuel injected and the precise timing. The new strategies are considered to cover the entire chamber space and inject the spray when it can yield the maximum work. In this light, the multiple injections strategy is proposed in many previous researches (Li et al. 2004; Mendez, Thirouard 2009; Lim et al. 2010; Badami et al. 2002) to reduce the amount of emissions drastically. It is reported that separating the

*E-mail: haditaghavifar@yahoo.com 
injected fuel into two pulses is an efficacious method to increase the ignition delay, which in turn reduces the $\mathrm{NO}_{\mathrm{x}}$ production in combustion (Husberg et al. 2008).

Mobasheri and Peng (2013) performed an investigation on application of different diesel fuel injection schemes while a modified homogeneity factor was introduced to measure the uniformity of air/fuel mixture. The results indicated that enlarging the dwell time between pulses leaves higher chance for mixing process to take place, hence the homogeneity factor increase and more complete combustion is attainable. In another research by Mobasheri et al. (2012), the combined effect of EGR and split injection was studied to keep emissions low and boost the engine performance in a numerical work. The main finding of research highlights that applying a proper amount of fuel during post-injection and adopting EGR can reduce soot emission without any increase in $\mathrm{NO}_{\mathrm{x}}$. Divergent injection with two nozzles are studied previously in researches by Taghavifar et al. (2016), Anvari et al. (2016), in which two sprays are issued from two nozzles. The results showed that multi-hole nozzles are capable of enhancing the spray quality, thereby improving the mixture uniformity. The simultaneous effect of swirl and split injection together have been analysed in researches by $\mathrm{Li}$ et al. (2016a, 2016b) in a double swirl chamber of diesel engine. It was reported that swirl + split injection can improve the fuel/air mixture formation and reduce soot content, while in a double swirl system, an "acceleration effect" is a key factor for the engine better performance.

The CFD methodology is taken into account to use advanced injection system, in which two nozzles with diverged angles have been used to inject the fuel during two pulses to different places in the chamber. The injected fuel for the studied split injection was kept constant as of the injected fuel mass in the single injection case. The variant parameters effect on the engine performance and emissions are dwell time between pulses, the angle between nozzles, and the mass ratio between two injected pulses. The results show a step forward from the single injection and multiple injections from single nozzle to a fixed point into the combustion chamber.

\section{Numerical simulation and modelling procedure}

\subsection{Model and problem description}

A HSDI Ford 1.8 L diesel engine (Hawley et al. 2003) is taken to study the combustion phenomena as a result of split injection with divergent spray angles. The engine is 4-cylinder, turbocharged, air-cooled, four-stroke, and DI diesel engine. The source engine is equipped with a HPCR system, which allows for multiple injections per cycle over the wide operational range. The fuel is injected asynchronously without overlap between pulses to the bowl and crevice sections of the combustion chamber. The injected fuel either in the single injection or different cases of split injection is constant and based on experimental work corresponds to $31.3 \mathrm{mg} / \mathrm{cycle}$. Three levels of 10, 20 and
$30 \mathrm{deg}$ are considered for the angles of two nozzles, where the position of the lower nozzle is fixed 140 deg with respect to $x$ axis while the second nozzle divert 150, 160 and 170 deg from $x$ axis. The labelling and symbols used to identify different injection schemes represent the share of injected fuel in the first and second pulse, while the given number between parentheses denote the dwell time between two pulses and the last number after dash gives the divergence angle between nozzles.

For having a better understanding of how the new injection method works and be familiar with the concept of injection pulses and dwell time, Figure 1 is illustrated giving different injection profiles as compared to a single injection. The whole injection time is constant equal to 22 deg CA for different injection schemes and the simulations are carried out at medium load under $2500 \mathrm{rpm}$ engine speed.

The combination of injection angle, injection timing induces different pattern of swirl hence mixture formation in the combustion chamber. In Figure 2, a schematic of a typical advanced injection scheme 70(10)30 $30 \mathrm{deg}$ is mentioned to help readers gain a clear interpretation of what happens inside the engine. The first injection is issued into the bowl area (in solid red colour arrow) at $4 \mathrm{deg}$ CA BTDC carrying $70 \%$ of fuel mass $(2.62 \mathrm{mg} /$ cycle). In this state, the engine is in the upper place moving upwards

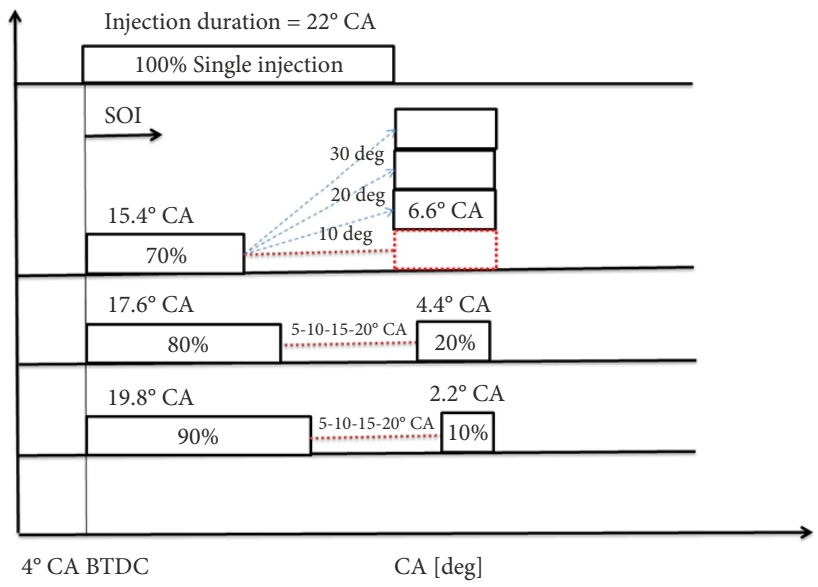

Figure 1. Injection profiles for different injection arrangements along the CA evolution

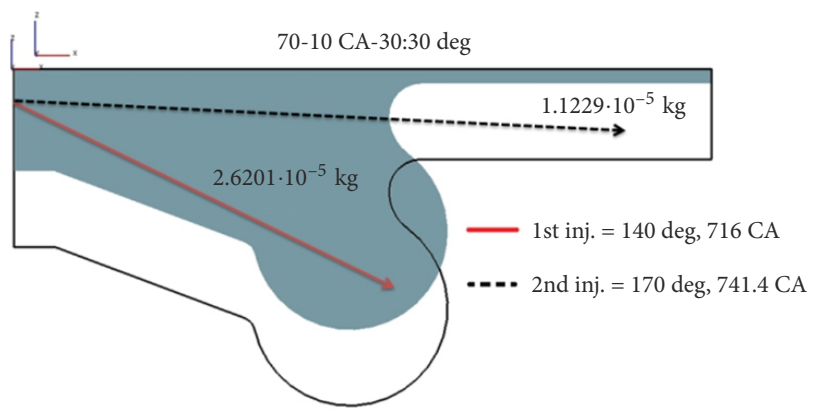

Figure 2. A schematic of the proposed divergent split injection for a typical case of 70-(10)-30 $30 \mathrm{deg}$ 
to TDC. After the first injection is completed, there would be $10 \mathrm{CA}$ rest until the second injection (shown in black dashed line) is injected to crevice containing $30 \%$ of fuel mass $(1.1229 \mathrm{mg} / \mathrm{cycle})$. The status of engine is outlined in black and the chamber is sweeping downwards to BDC.

\subsection{The engine simulation procedure}

For a numerical study, the obtained results are functions of the meshing cells until reaching a point where the results are free from grid dependency. Therefore, Figure 3a is provided to demonstrate the pressure curves change in three meshing resolutions. The meshing domain is comprised of 23623 cells, which is optimum case that gives valid responses without inflicting the computations with timely software runs. The meshed geometry of combustion chamber at TDC for a quarter portion of the whole domain for the baseline case is shown in Figure 3b. In order to test the reliability of created model, it has to be validated according to measured data.

For solving the discretized conservative Navier-Stokes equations corresponding to flow field the finite volume approach is adopted. The Semi-Implicit Method for Pressure-Linked Equations (SIMPLE) algorithm is very suitable to solve the highly unsteady state flow of combustion problem (Patankar 1980). For spray injection, the Discrete Droplet Method (DDM) is applied to explain spray droplet distribution; in the meantime, the modified Kelvin-Helmholtz/Fayleigh-Taylor (KH-RT) model is responsible for the secondary atomization of spray (Beale, Reitz 1999). The highly turbulent fluid flow because of

a)

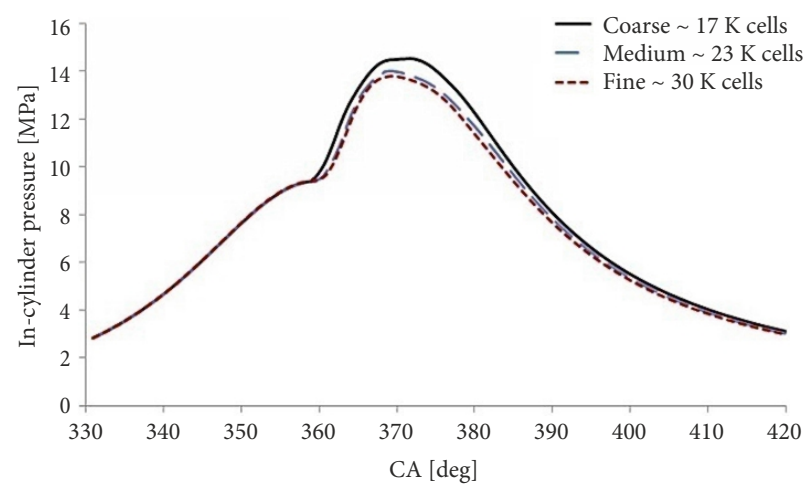

b)

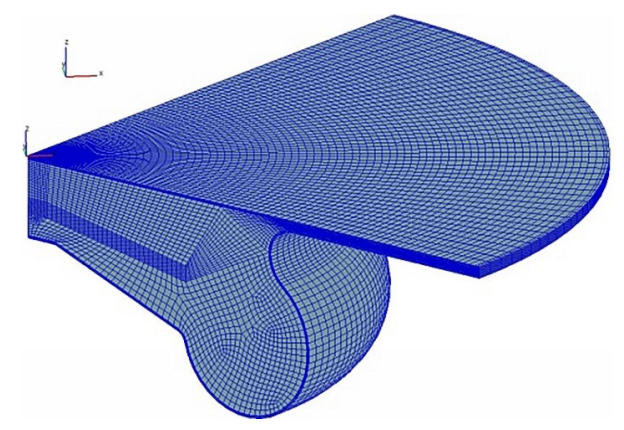

Figure 3. Grid resolution effect on pressure course (a) and grid used for the model at TDC position (b) combustion onset in the combustion chamber should be modelled, without which prediction of thermodynamic characteristics is impossible, thus, the flow turbulence is introduced by the $k-\zeta-f$ model. In order to enhance the stability and convergence of the simulation procedure, the initial stage of calculation is implemented in $\Delta \alpha=0.1 \mathrm{CA}$ step. Then for the compression stroke before injection to increase the speed of program it was increased to in $\Delta \alpha=$ $1 \mathrm{CA}$, finally at the injection time and combustion period the step size is divided to in $\Delta \alpha=0.2$ CA. In the discretization process, calculation of boundary values is based on extrapolation and calculation of derivatives is with least square fit. The under-relaxation factors for momentum, pressure, and energy are set $0.6,0.5$ and 0.95 for preserving precision of results. Convergence criteria per CA are 10 and 100 for the minimum and maximum number of iterations, respectively. For heat-up and evaporation of the fuel spray droplets, the Dukowicz model (Dukowicz 1979) was applied in the developed code. The interaction between the fuel spray particles and the turbulent eddies as a result of fluctuating velocity has to be included in the mean gas velocity by a stochastic dispersion model (Liu et al. 1993). The multi-zone ECFM-3Z is used for modelling the intricate combustion incident in the combustion chamber (Colin, Benkenida 2004) and the "Extended Zeldovich" mechanism is able to predict the $\mathrm{NO}_{\mathrm{x}}$ content in an acceptable accuracy. The applied boundary and initial conditions as well as required sub-models are detailed in Table 1. The main operational features of the diesel engine setup are mentioned in Table 2. The geometry of 1:4 of chamber is initially designed and meshed in AVL ESE Diesel interface toolkit through modification of available templates, and then it is transferred to Fire Workflow Manager (WFM) of AVL Fire to set boundary condition, initial condition, linearization method, discretization algorithm, convergence criteria, etc.

IMEP is a valuable indication of the engine ability to deliver work and is defined as an average pressure generated during the power course. This factor can be described as following:

$$
I M E P=\frac{1}{V_{D}} \cdot \int P_{C} d V
$$

where: $V_{D}$ is displacement volume; $P_{C}$ represents the cylinder pressure.

One of the parameters included in the objective function is IP, which has direct relation with IMEP as:

$$
P_{i}=I P=I M E P \cdot V_{D} \cdot n_{c y c l e},
$$

where: $n_{\text {cycle }}=n / 2 ; n$ is crankshaft revolution per second.

The second important parameter to measure the engine efficiency is ISFC formulated as:

$$
I S F C=\frac{m_{t, F V} \cdot n_{c y c l e}}{P_{i}},
$$

where: $m_{t, F V}$ express the injected fuel mass to cylinder. 
Table 1. Boundary and initial condition with main submodels of simulation

\begin{tabular}{|l|l|}
\hline Head temperature & $550.15 \mathrm{~K}$ \\
\hline Piston temperature & $575.15 \mathrm{~K}$ \\
\hline Cylinder temperature & $475.15 \mathrm{~K}$ \\
\hline Spray breakup & Modified KH-RT \\
\hline Combustion model & ECFM-3Z \\
\hline Turbulence model & $k-\zeta-f$ \\
\hline Evaporation & Dukowicz \\
\hline NO & Extended Zeldovich \\
\hline Fuel injection quantity & $31.3 \mathrm{mg} /$ cycle \\
\hline Residual gas ratio & 0.5 \\
\hline Initial pressure & $0.1 \mathrm{MPa}$ \\
\hline Initial temperature & $330 \mathrm{~K}$ \\
\hline Injection valve closed & 52 deg CA ATDC \\
\hline Exhaust valve open & $110 \mathrm{deg}$ CA ATDC \\
\hline
\end{tabular}

Table 2. Engine specifications

\begin{tabular}{|l|l|}
\hline Bore $\times$ stroke & $82.5 \times 82 \mathrm{~mm}$ \\
\hline Displacement & $438 \mathrm{~cm}^{3} /$ cylinder \\
\hline Compression ratio & $19.5: 1$ \\
\hline SR @ IVC & 3 \\
\hline Rail pressure & $\begin{array}{l}540 \ldots 1255 \text { bar } \\
(\text { based on engine speed })\end{array}$ \\
\hline Nozzle geometry & $5 \times 0.15 \mathrm{~mm}$ \\
\hline Number of nozzles & 4 \\
\hline Clearance & $0.86 \mathrm{~mm}$ \\
\hline Connecting rod length & $104 \mathrm{~mm}$ \\
\hline Injection start timing & $3 \mathrm{deg}$ CA BTDC \\
\hline Injection spray angle & $160 \mathrm{deg}$ \\
\hline
\end{tabular}

For validation of the baseline single injection, the results of pressure course obtained by modelling approach is compared to that of measured via experimental setup under $2500 \mathrm{rpm}$ in Figure 4a. As shown, the accuracy of model in predicting the engine behaviour can be verified since the maximum error tolerance is less than $3 \%$ at the peak pressure. Moreover, the cumulative heat release from the base engine obtained from experimental facility (Hawley et al. 2003), in the single injection mode, is compared with that of simulation results in Figure $4 \mathrm{~b}$. It is observed clearly that the numerical trend traces the measured heat release within $\pm 1 \%$ tolerance range confirming the robustness of model.

\section{Results and discussion}

The numerical tests were performed based on a $1.8 \mathrm{~L}$ prototype of a HSDI diesel engine equipped with HPCR system to provide the advanced flexible injection with high speed and pressure. To establish a flexible fuel injection and air charge, VGT and HPCR systems are assembled. The HPCR system makes sure that the fuel injection pres-

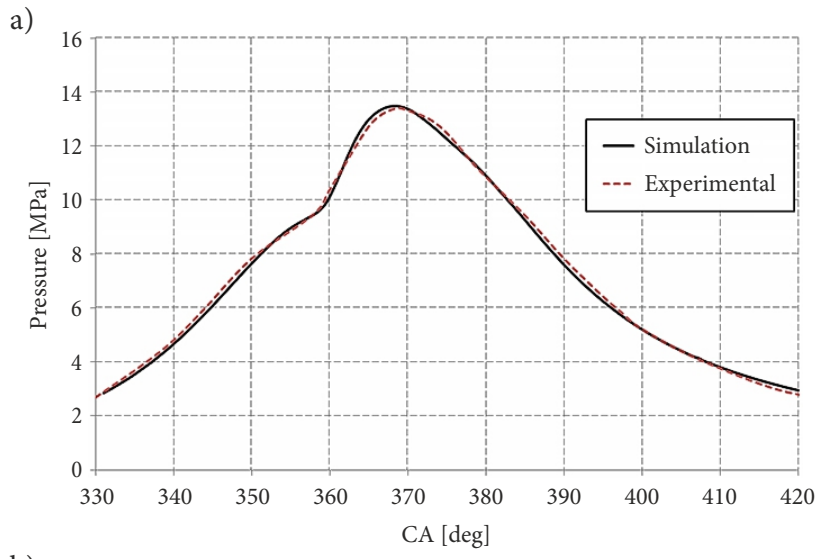

b)

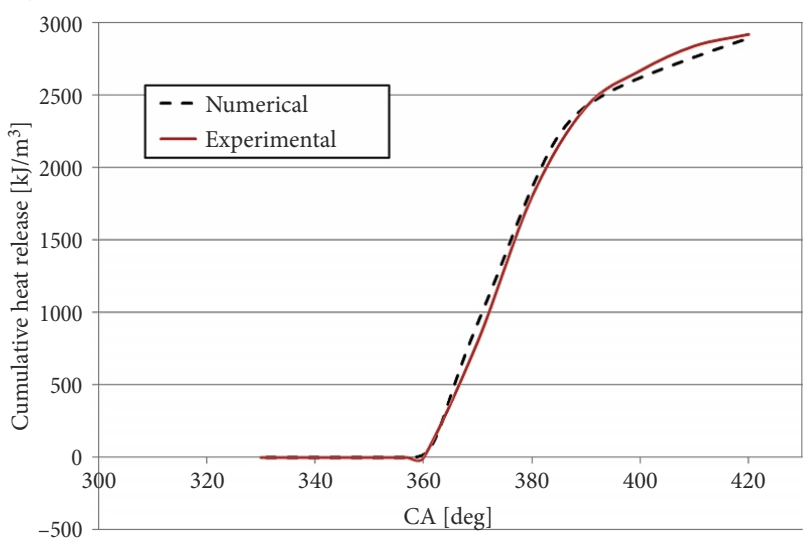

Figure 4. The comparison of calculated results by modelling and the experimental data for: a - in-cylinder pressure at $2500 \mathrm{rpm}$; $\mathrm{b}$ - cumulative heat release at $3500 \mathrm{rpm}$ (Hawley et al. 2003)

sure is operating irrespective of crankshaft speed, which subsequently a more uniform air/fuel mixture can be obtained. The experiments were undertaken under the LTC of a Ford DI diesel engine with a built-in model of a FGT with a distributor electronic fuel injection system. HSDI Ford diesel engine was equipped with a prototype Lucas $C A V$ HPCR system, and an Allied Signal VGT. All dataset were measured at relatively early stages of the commissioning process of the equipment. Since a needle lift transducer was not available, the start of injection had to be interred from the instant where the raise pressure trace shows its first reduction. AVL 409 Smoke (Bosch) and AVL AFR (Spindt) were used for measurement of smoke and air/fuel ratio (Hawley et al. 2003). In the simulation process though, two injectors are installed for the chamber with divergent angle and the timing and span of each injections with respective dwell times are scheduled as shown in Figure 1.

\subsection{Effect of diverge split injection on engine performance and emissions trade-off}

In order to identify the position of different injection schemes and to compare with the baseline single injection, Figures 5 and 6 are provided; thereby gain a global overview of the overall ISFC-soot and IMEP-NO $\mathrm{NO}_{\mathrm{x}}$ configuration. In this manner, one can easily choose the point 
of interest in engine performance - emissions conflict. According to Figure 5, it is seen that adopting divergent split injection the engine power can be increased compared to single basic injection. This is resulted from timely injection of spray as well as a proper location of spray droplet distribution in chamber, which terminates in better utilization of fuel chemical potential. Another point is that among all

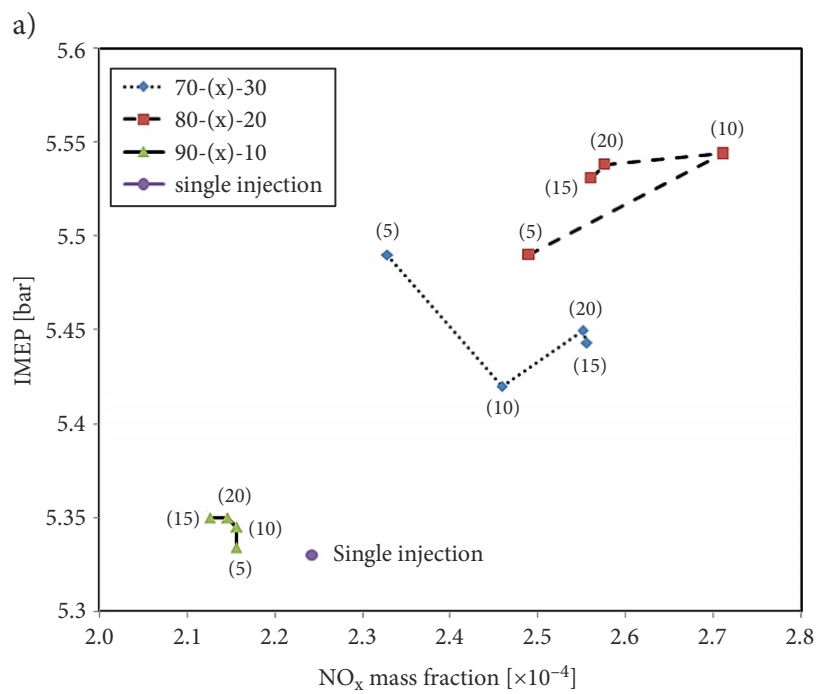

b)

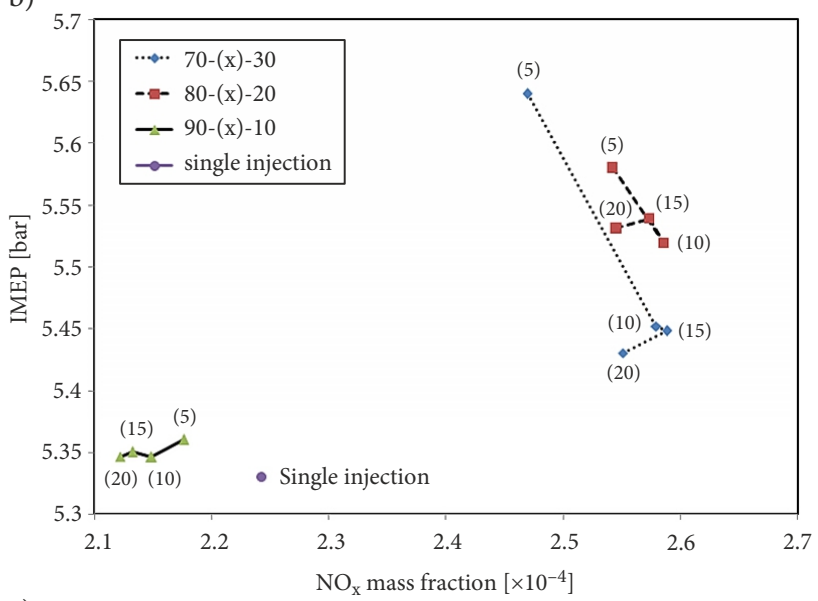

c)

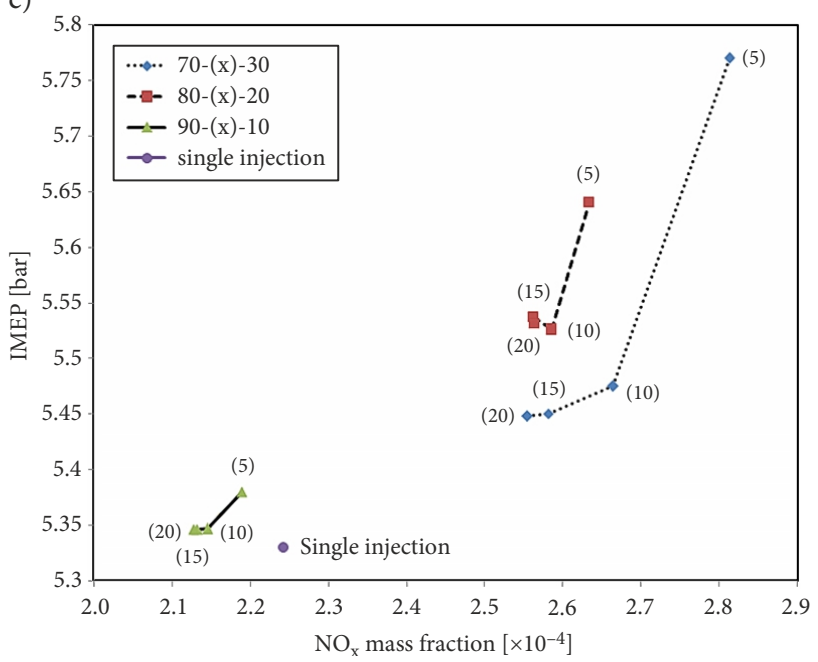

Figure 5. IMEP vs. NOx plot for various injection schemes under nozzle divergence: $\mathrm{a}-10 \mathrm{deg}$; $\mathrm{-}-20 \mathrm{deg}$; $-30 \mathrm{deg}$ cases with different inter-angles, 90-(x)-10 gives the poor performance (low IMEP and high ISFC), which is close to single injection operational point, since the form of two sprays are so close almost like a single spray mode. The collision and coalescence of spray droplets are frequently observed in 90-(x)-10 plus the fuel distribution over pulses has no perceptible dissociation. The general trend in IMEP-NO $\mathrm{NO}_{\mathrm{x}}$ plots reads power dominancy of 70-(x)-30 scenario when $5 \mathrm{CA}$ dwell is laid between two injection pulses for 20 and 30 deg inter-nozzle angles. For the case of 10 deg injection angles of sprays, 80-(x)-20 outperform others. In an IMEP-NO $\mathrm{NO}_{\mathrm{x}}$ compromise as shown 80-(x)-20 in all graphs is recommended (the reason goes to the HRR curves 80-(x)-20 demonstrate higher PMC than those of other scenarios).

With reference to Figure 5, the dwell time of $5 \mathrm{CA}$ leads to higher engine power and efficiency for all injection schemes of 70-(x)-30, 80-(x)-20 and 90-(x)-10 and for 20 and 30 deg of inter-nozzle spraying. With increasing the time gap between the first and second injection pulses, the heat transfer and high-pressure production is being shifted from expansion to exhaust stroke, consequently the thrusting pressure resulted from the burning of second pulse injection would not be exerted on piston. In addition, delaying of second pulse injection cause some of the injected fuel of second pulse lose the chance to release its chemical energy of combustion and hence is wasted, which inflicts the system with high ISFC. Therefore, retarding of second pulse injection must be prevented as much as possible, unless the designer has tendency to reduce the $\mathrm{NO}_{\mathrm{x}}$ emission.

From the $\mathrm{NO}_{\mathrm{x}}$ emission prospective, 90-(x)-10 distribution exhibits the lowest content due to lower heat release of second injection phase of 90-(x)-10 in HRR. Lower heat generation together with low in-cylinder temperature (Figure 7) is attributable to comparative low $\mathrm{NO}_{\mathrm{x}}$ for 90-(x)-10. Figure 6 shows ISFC vs. soot curves for different injection schemes as well as single injection of conventional case. Applying the proposed divergent split injection, the amount of fuel consumption has been decreased, while soot is relatively lower for most of 70-(x)-30 and $90-(\mathrm{x})-10$ cases. The least soot content is of 70-(x)-30 scheme in which soot can be reduced considerably. Since soot emission is under the influence of flow regime inside the chamber, fuel/air uniformity, in-cylinder temperature for oxidation of soot, and fuel injection in squish area. All of these factors have to be taken into account in soot variation analysis. According to Figure 7, the highest temperature belongs to $70-(\mathrm{x})-30$, which expedites the oxidation of soot and its depletion in the engine.

\subsection{Effect of diverge split injection on combustion and in-cylinder flow dynamics}

For a single injection, the temperature gradually decreases with CA. However, for the split injection due to injection of the second pulse, the temperature increases again thereby the high-temperature and high-pressure gas can thrust 
the piston down strongly and deliver the work with higher rate. It is obvious that $30 \mathrm{deg}$ inter-nozzle angle present higher temperature peak and power that is linked directly with the flow characteristics inside the combustion chamber such as swirl, turbulence, and mixture formation.

The swirl flow and mixture quality are quantified and characterized with SR and UI. Figure 8 plots the UI of the

a)
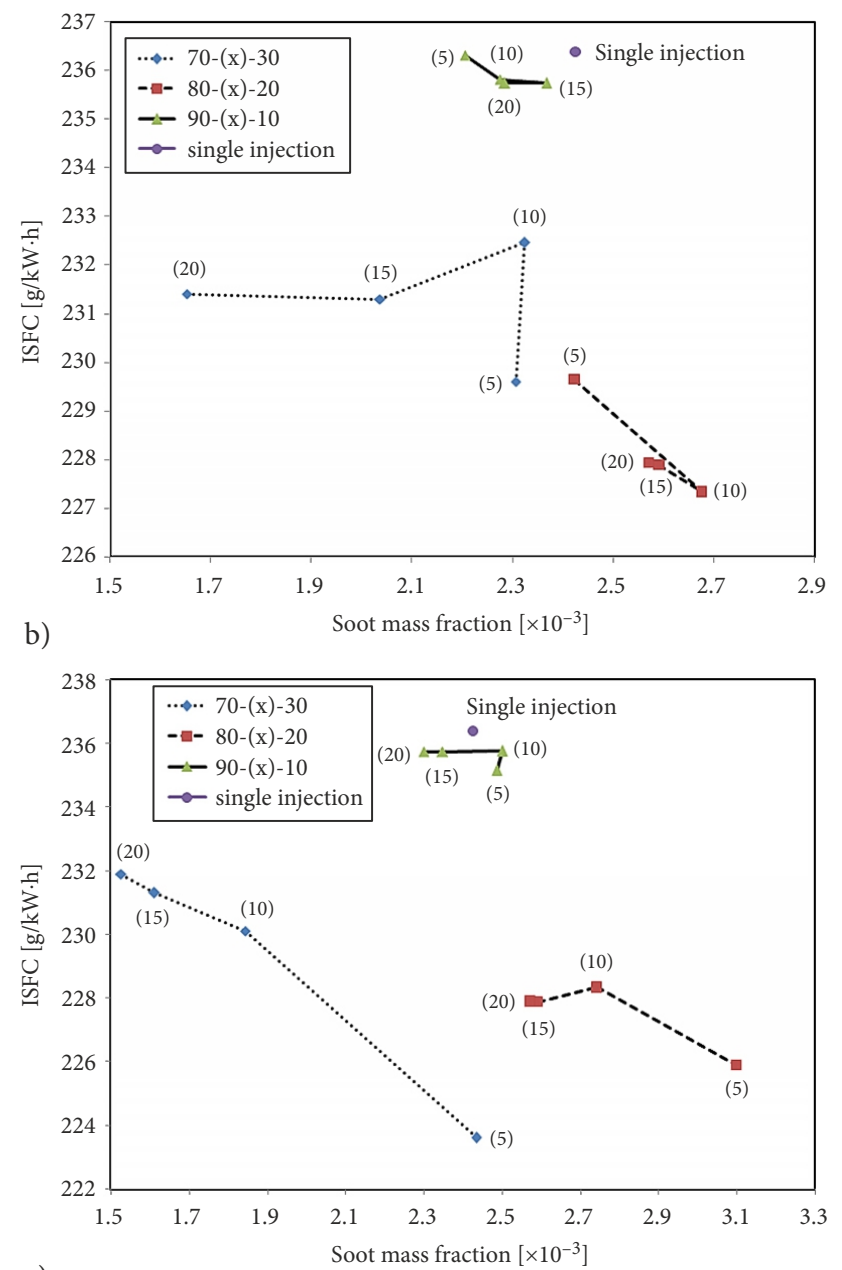

c)

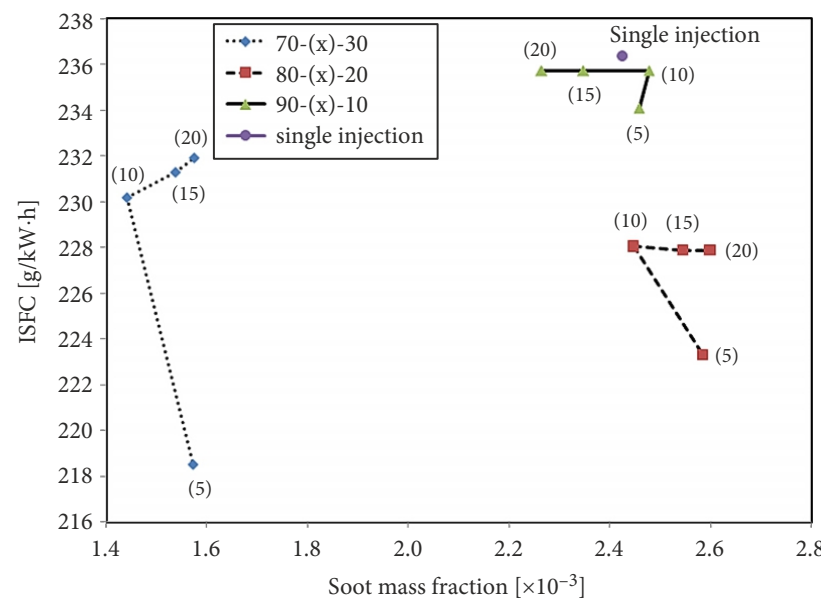

Figure 6. ISFC vs. soot plot for various injection schemes under nozzle divergence: $\mathrm{a}-10 \mathrm{deg}$; $-20 \mathrm{deg}$; $-30 \mathrm{deg}$ best cases in terms of the engine power for different dwell time of $70 \ldots 30,80 \ldots 20$ and $90 \ldots 10 \%$ schemes as a function of CA. It can be inferred that among all inter-spray angles of 10, 20 and $30 \mathrm{deg}$, the highest uniformity belongs to $70 \ldots 30 \%$ fuel distribution share between pulses. The higher uniformity of 70-(x)-30 explains the low soot emission and high temperature course formerly observed. It is due to this high degree of uniformity that $70 \ldots 30 \%$ strategy shows the greatest heat release peak in MCC combustion phase (combustion of second pulse injection).

The HRR histories of different split injection strategies of 10, 20 and 30 deg divergent sprays are shown in Figure 9. It is seen that the highest values of the second phase of heat release is in the following order 70-(x)-30, 80-(x)-20 and 90-(x)-10 for different inter-nozzle angle arrangements. It can be concluded that the strategies, which give more second phase heat (or diffused controlled combustion phase) correspond to ones with better engine performance metrics. The more diverged the nozzle angles

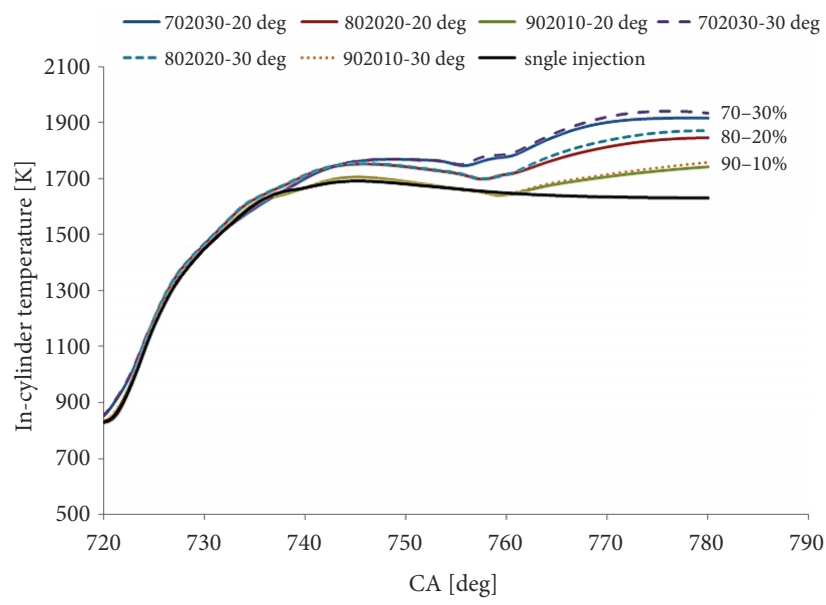

Figure 7. Variation of the engine temperature for various injection schemes of 20 and 30 deg nozzle divergence

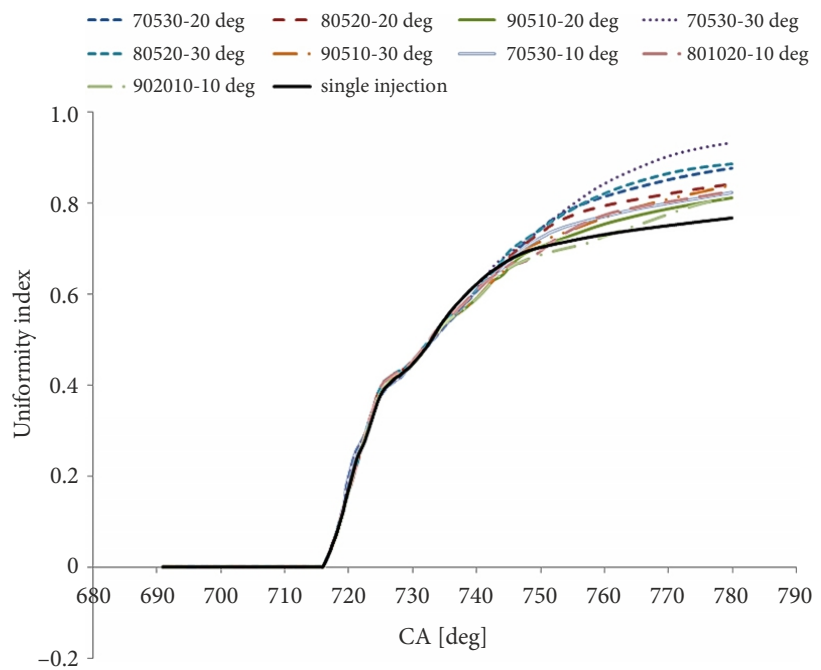

Figure 8. Evolutionary trend of UI for the mixture formation against CA for different injection schemes 
are, the higher extent of heat release in second injection is observed such that for example in 70-(5)-30, the HRR peak for 10, 20 and 30 deg associate with 19.836, 22.059 and $25.0504 \mathrm{~J} / \mathrm{deg}$. The proximity on nozzle angles allows for spray droplet collision, coalescence, thereby increasing the probability of spray-wall collision in upper bowl throat area, hence combustion deterioration. In addition, the divergence of nozzle angles results in penetration of more

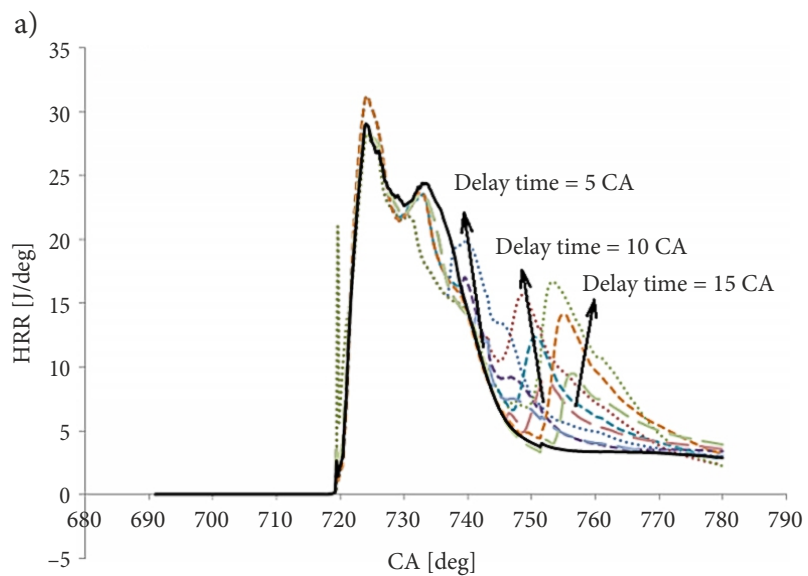

b)

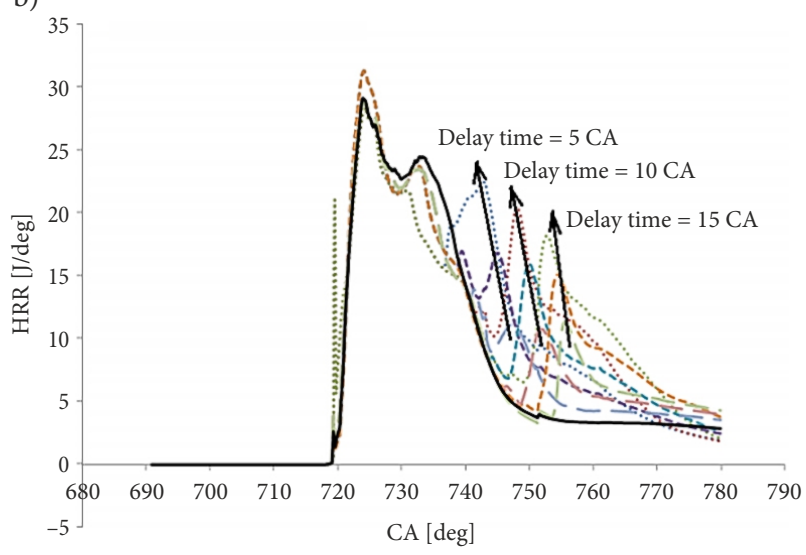

c)

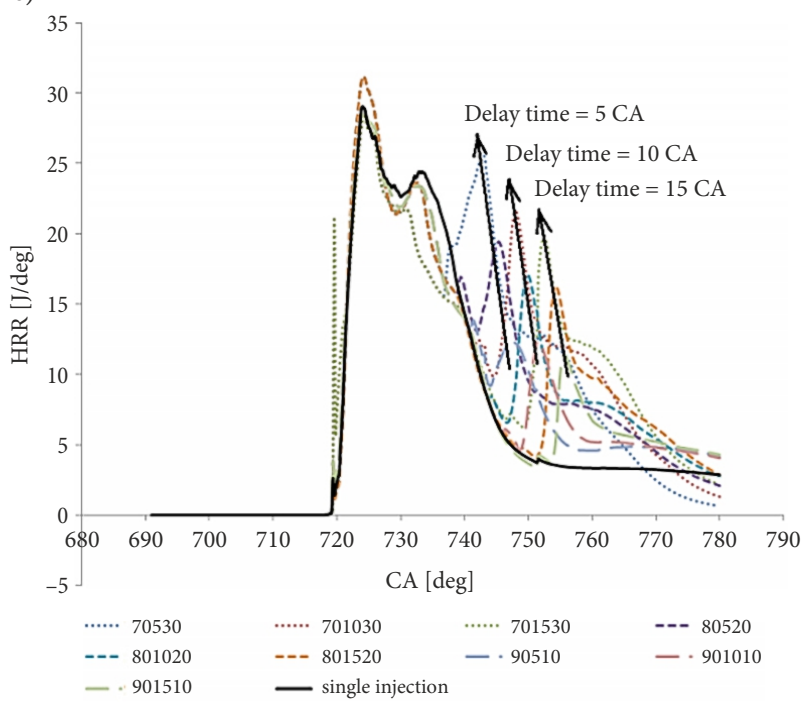

Figure 9. HRR histories against CA for various injection schemes under nozzle divergence: $\mathrm{a}-10 \mathrm{deg}$; $\mathrm{-}-20 \mathrm{deg}$; -30 deg fuel into crevice, where the oxygen is abundant and helpful in higher fuel burning rate. Taken 70-(5)-30, the hot gas as a result of combustion is more viable to generate propelling force and create higher IMEP. Nonetheless, increasing the dwell time between pulses plays an adverse role in the engine efficiency. That is to say, the hot gas products of combustion lose the chance to increase the pressure and majority of it is depleted during exhaust stroke.

Based on what explained up until now, bar diagram of IP for the optimum cases of 10, 20 and 30 deg inter-nozzle angles is illustrated in Figure 10. As shown, diverting the nozzle angle from 10 ...30 deg the engine out power is also increasing, since the corresponding UI for the $30 \mathrm{deg}$ is largely higher than that of other cases. Taken together, the UI of split divergent injection in the best way - 70-(5)30 - is 0.932778 , which is much better than that of single injection with $\mathrm{UI}=0.768551$.

With regard to fuel distribution in combustion chamber, 3D contour plots for ER are shown in Figure 11 for one of the cases of $70 \ldots 30,80 \ldots 20$ and $90 \ldots 10 \%$ among 10, 20 and 30 deg configurations, which had the lowest soot content. It can be vividly seen that 70-(x)-30 strategy of fuel distribution over pulses demonstrate lower ER close to unity, hence more homogenous mixture is found within combustion chamber. It comes with implications; first, the uniform mixture has more accessibility to sufficient oxygen for evaporation of the majority of droplets, then maximum utilization of heating value of the fuel occurs. Second, the lower ER means tiny, well-atomized droplets of spray can burn effectively and reduce soot emission. There is an interesting point that at $750 \mathrm{deg}$ CA position, increasing the inter-nozzle angle sweep the high concentration region from inside the bowl (10 deg) into the extreme end of squish (30 deg) where rich oxygen is beneficial for rapid burning rate.

In the following flow analysis, the velocity field together with final SR values for each injection strategy is depicted in Figure 12. Figure 12a and Figure 12b illustrates the velocity field related to the least and the most concentration of $\mathrm{NO}_{\mathrm{x}}$ and soot, respectively in three levels of 10 , 20 and 30 deg inter-nozzle angles at $750 \mathrm{deg}$ CA position.

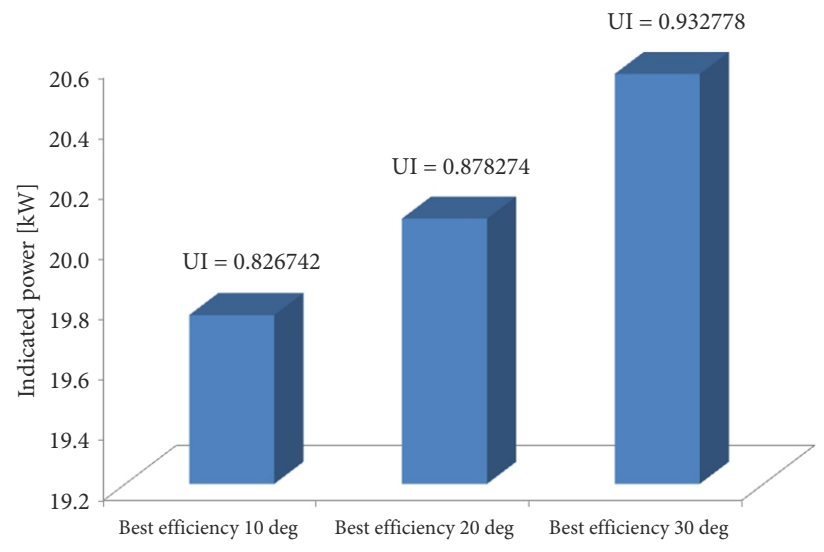

Figure 10. Comparison of IP for the best engine performance at different inter-nozzle angles 
a)

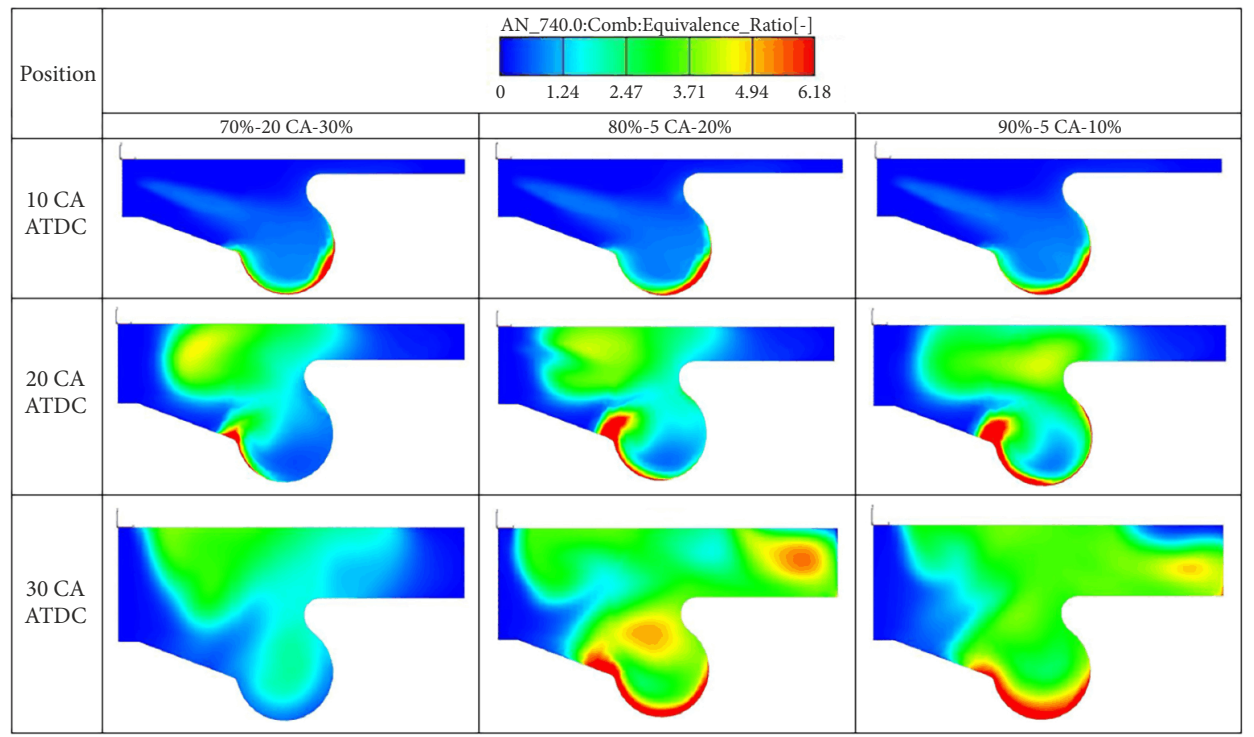

b)

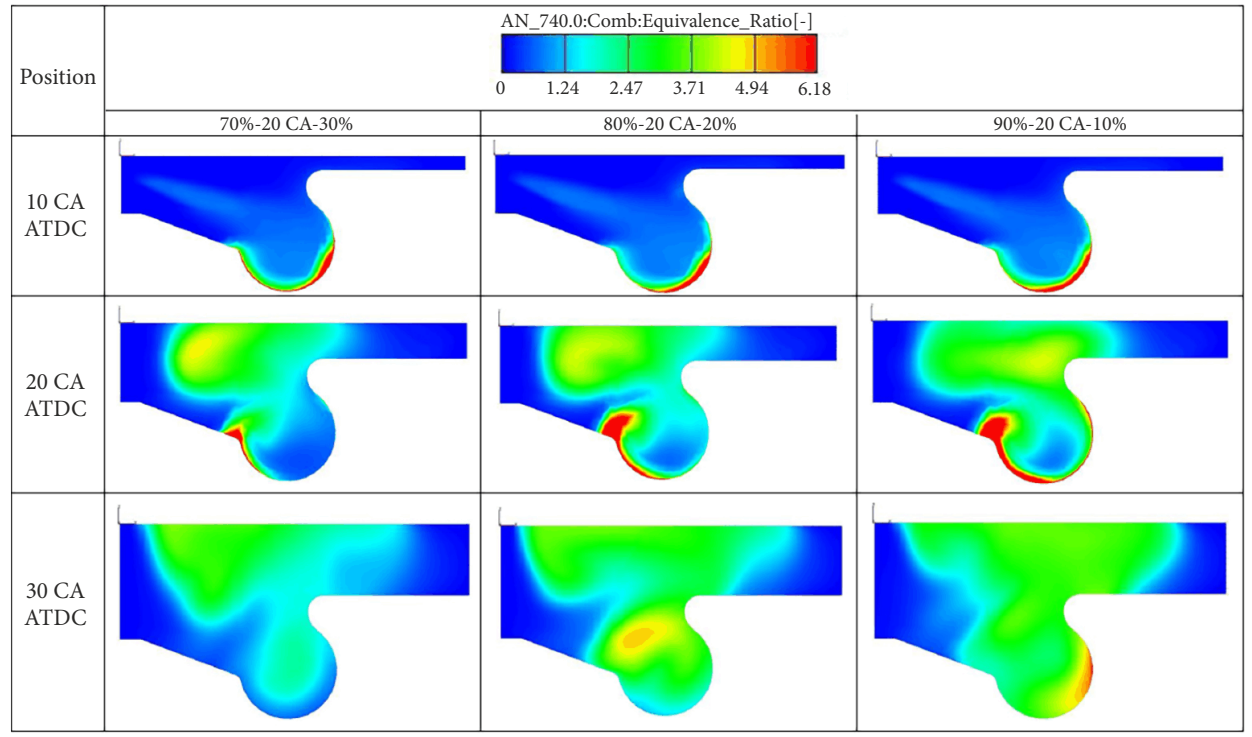

c)

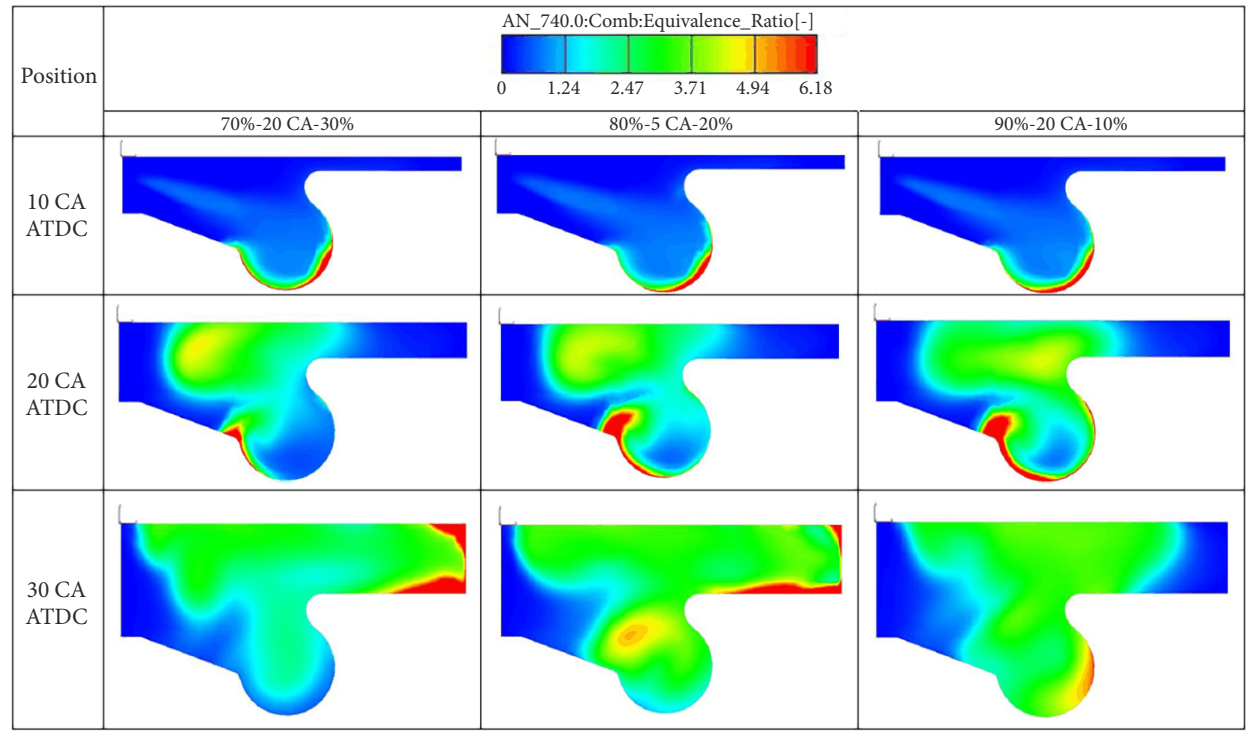

Figure 11. Contour plots of ER at 730, 740 and 750 deg CA for different injection strategies with the east soot content under nozzle divergence: $\mathrm{a}-10 \mathrm{deg}$; $\mathrm{b}-20 \mathrm{deg}$; $-30 \mathrm{deg}$ 
a)

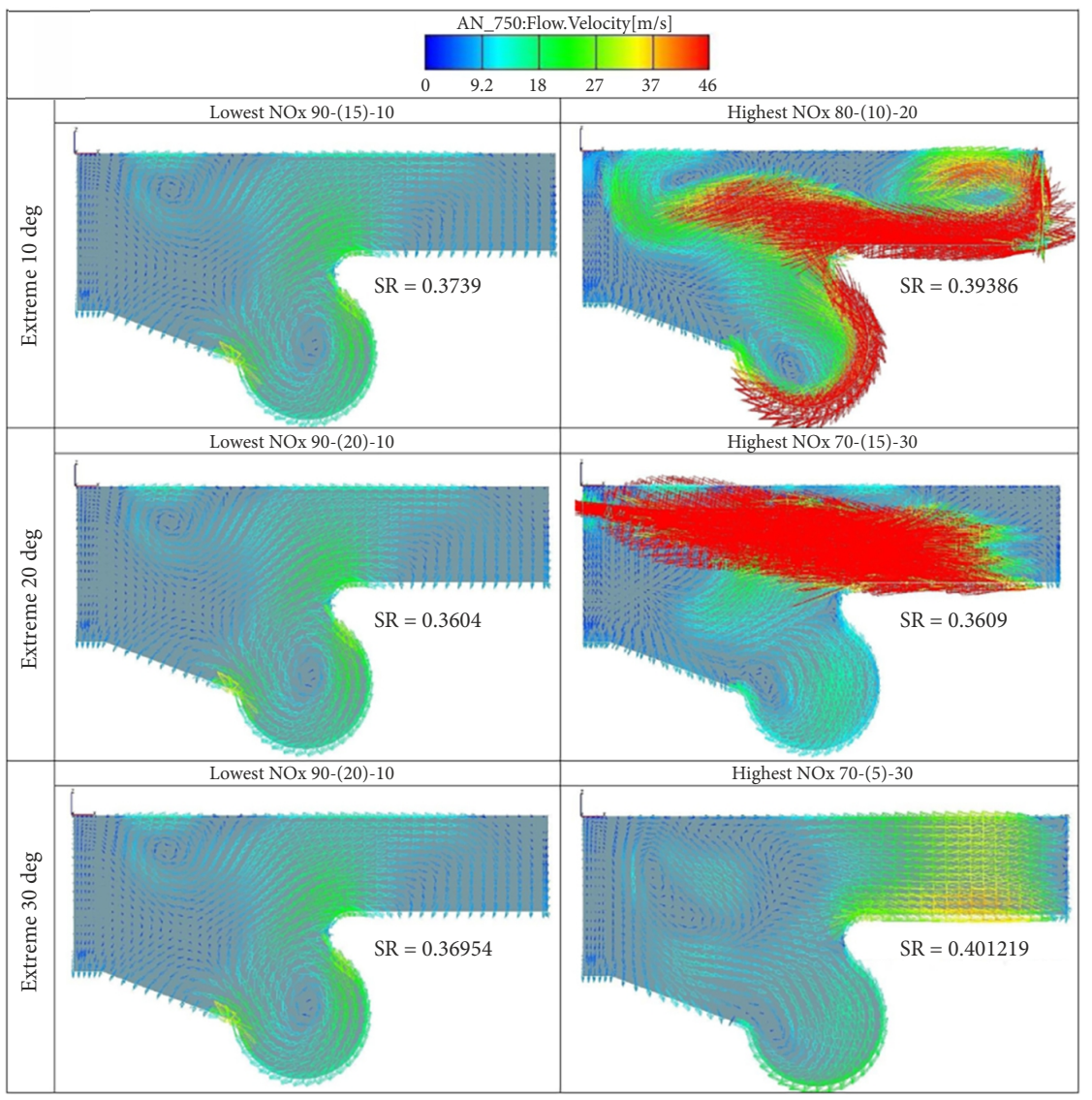

b)

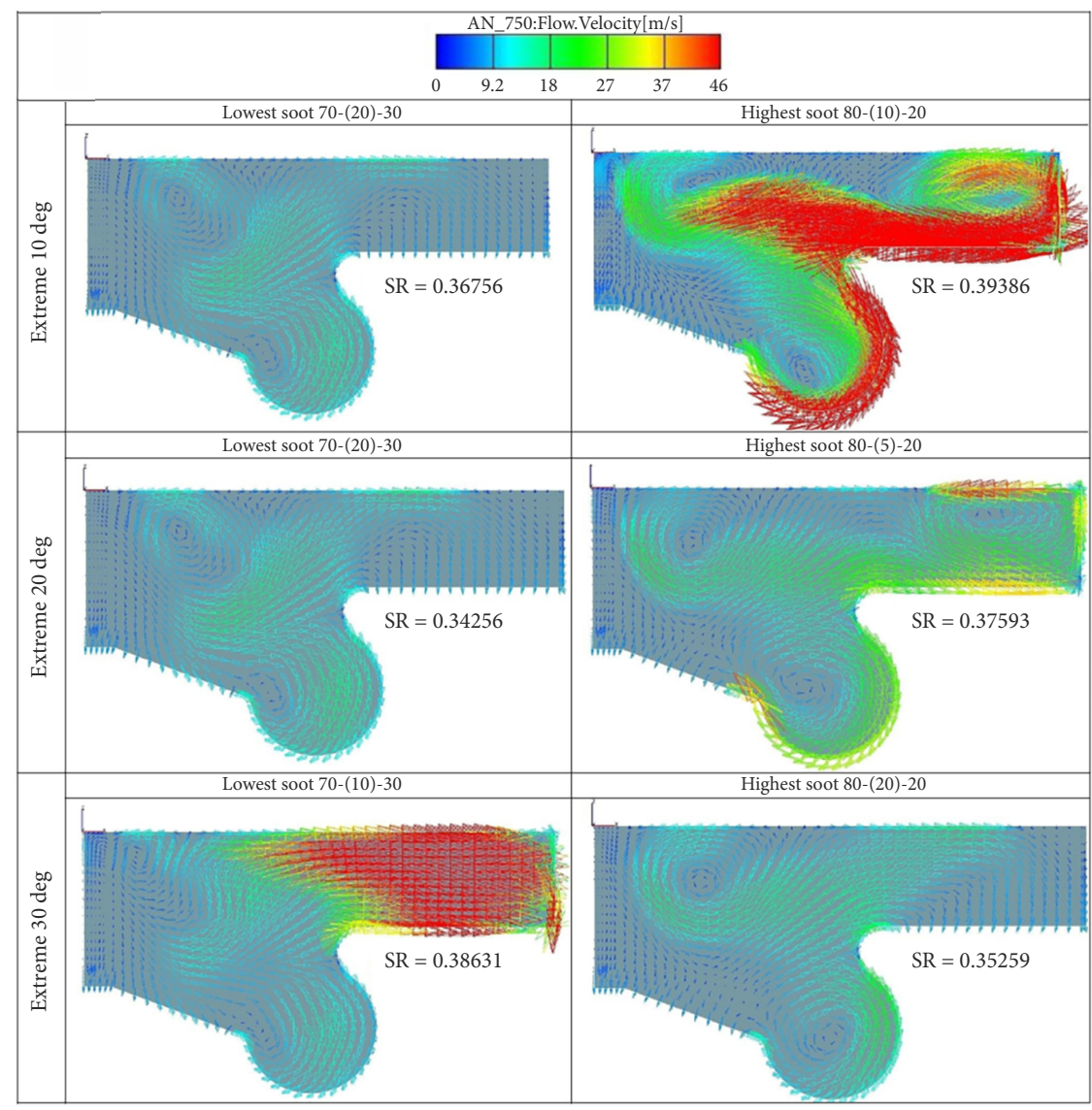

Figure 12. The flow field and velocity vectors along with final SR for the maximum and minimum amounts of $\mathrm{NO}_{\mathrm{x}}(\mathrm{a})$ and soot (b) under 10, 20 and 30 deg nozzle divergence 
From Figure 12a, it can be appreciated that taken higher SR and strong velocity field, the flow has been whirled and mixed intensively making the mixture more homogenous leading to a complete combustion with higher rate. The immediate impact of better combustion is the rise of temperature, which produce thermal $\mathrm{NO}_{\mathrm{x}}$ accordingly. Based on Figure 12b, although the highest swirl and the strongest velocity (that are influential factors in spray breakup and soot reduction) match with the highest soot distribution across the chamber but one has to notice that higher velocity cause spray-wall impingement increasing the soot formation. The aforesaid is not applicable for $30 \mathrm{deg}$ case and the reason can be traced to a very high temperature of 70-(x)-30 and oxidation of great share of soot.

Altogether, the conventional injections are either single-portion spraying or split injections with fixed angle aiming toward a particular spot in the chamber. However, the flexibility of divert split injection allow better timing of injection to avoid excessive wall-impingement, access the blind spots of the chamber space, and thereby make the most of oxidizer for a better homogeneity of air-fuel mixture. In this way, the combustion of sprayed fuel takes place in two phase yielding an economized fuel utilization $(7.56 \% \downarrow$ fuel consumption with respect to single injection), effective pressure boost $(8.25 \% \uparrow$ compared to single injection), and simultaneously lower $\mathrm{NO}_{\mathrm{x}}$ /soot emissions. Since the study is numerical, the limitations of the study is manufacturing the new generations of injectors with different inclination angles together with actuators to appropriately have the timing adjusted by computer programming. The production of such injection technology with variable angle and timing is the main challenge that has to be addressed.

\section{Conclusions}

A CFD code has been utilized in the AVL Fire framework to examine the effect of divergent split injection on a Ford 1.8 L HSDI diesel engine. Combustion analyse is performed via ECFM-3Z as to understand emission species prediction more accurately. In the implementation process, a second nozzle is installed in the combustion chamber targeting the fuel injection at the upper angle especially towards the squish zone. The angle between two nozzles is considered at three levels of 10, 20 and 30 deg. Besides, the entire fuel mass is allocated in $70 \ldots 30$, $80 \ldots 20$ and $90 \ldots 10 \%$ shares between the injection pulses with different angles. In addition, the pulses are separated with dwell times of 5,10, 15 and 20 deg CA. Altogether, 36 different cases were run by computer to consummate the research program. The following are the gist of concluding remarks:

For the better understanding of the flow pattern in the combustion chamber in terms of the engine efficiency and mixture formation because of the novel split injection, two parameters of swirl number and UI have been incorporated into the coded program as UDF. Increasing the SR led to $\mathrm{NO}_{\mathrm{x}}$ augmentation, though it did not show any meaningful relation on soot content. However, UI showed a direct impact on the engine power and engine performance such that increasing the nozzle divergence would increase the UI and also the engine power.

Overall, the 80-(x)-20 injection set appropriates the best efficiency and engine performance metrics due to its potential in making a more homogenous mixture in combustion chamber. Although, exceptionally 70-(5)-30 for 20 and 30 deg inter-nozzle angles demonstrated the highest IP.

The important point with regard to engine performance, it should be underlined that the second peak of HRR corresponds to the case with the highest engine power and IMEP. In other words, 70-(5)-30 possess the highest second peak of HRR, which by the way gives the highest engine power.

It can be confirmed that increasing the divergence of nozzle angles influence the homogeneity of mixture positively, thus for all injection policies, the optimum case of $30 \mathrm{deg}$ is desirable for engine power.

\section{References}

Anvari, S.; Taghavifar, H.; Khalilarya, S.; Jafarmadar, S.; Shervani-Tabar, M. T. 2016. Numerical simulation of diesel injector nozzle flow and in-cylinder spray evolution, Applied Mathematical Modelling 40(19-20): 8617-8629. https://doi.org/10.1016/j.apm.2016.05.017

Badami, M.; Mallamo, F.; Millo, F.; Rossi, E. 2002. Influence of multiple injection strategies on emissions, combustion Noise and BSFC of a DI common rail diesel engine, SAE Technical Paper 2002-01-0503. https://doi.org/10.4271/2002-01-0503

Beale, J. C.; Reitz, R. D. 1999. Modeling spray atomization with the Kelvin-Helmholtz/Fayleigh-Taylor hybrid model, Atomization and Sprays 9(6): 623-650.

https://doi.org/10.1615/AtomizSpr.v9.i6.40

Colin, O.; Benkenida, A. 2004. The 3-zones extended coherent flame model (ECFM3Z) for computing premixed/diffusion combustion, Oil \& Gas Science and Technology 59(6): 593609. https://doi.org/10.2516/ogst:2004043

Dukowicz, J. K. 1979. Quasi-Steady Droplet Phase Change in the Presence of Convection. Informal Report No LA-7997-MS). Los Alamos Scientific Laboratory, University of California, US. 20 p. https://doi.org/10.2172/6012968

Hawley, J. G.; Wallace, F. J.; Khalil-Arya, S. 2003. A fully analytical treatment of heat release in diesel engines, Proceedings of the Institution of Mechanical Engineers, Part D: Journal of Automobile Engineering 217(8): 701-717. https://doi.org/10.1243/09544070360692096

Husberg, T.; Denbratt, I.; Karlsson, A. 2008. Analysis of advanced multiple injection strategies in a heavy-duty diesel engine using optical measurements and CFD-Simulations, SAE Technical Paper 2008-01-1328. https://doi.org/10.4271/2008-01-1328

Li, T.; Nishida, K.; Zhang, Y.; Yamakawa, M.; Hiroyasu, H. 2004. An insight into effect of split injection on mixture formation and combustion of DI gasoline engines, SAE Technical Paper 2004-01-1949. https://doi.org/10.4271/2004-01-1949

Li, X.; Gao, H.; Zhao, L.; Zhang, Z.; He, X.; Liu, F. 2016a. Combustion and emission performance of a split injection diesel engine in a double swirl combustion system, Energy 114: 1135-1146. https://doi.org/10.1016/j.energy.2016.08.092 
Li, X.; Zhou, H.; Zhao, L. M.; Su, L.; Xu, H.; Liu, F. 2016b. Effect of split injections coupled with swirl on combustion performance in DI diesel engines, Energy Conversion and Management 129: 180-188.

https://doi.org/10.1016/j.enconman.2016.09.011

Lim, J.; Lee, S.; Min, K. 2010. Combustion modeling of split injection in HSDI diesel engines, Combustion Science and Technology 183(2): 180-201.

https://doi.org/10.1080/00102202.2010.519012

Liu, A. B.; Mather, D.; Reitz, R. D. 1993. Modeling the effects of drop drag and breakup on fuel sprays, SAE Technical Paper 930072. https://doi.org/10.4271/930072

Mendez, S.; Thirouard, B. 2009. Using multiple injection strategies in diesel combustion: potential to improve emissions, noise and fuel economy trade-off in low CR engines, $S A E$ International Journal of Fuels and Lubricants 1(1): 662-674. https://doi.org/10.4271/2008-01-1329

Mobasheri, R.; Peng, Z. 2013. CFD investigation into diesel fuel injection schemes with aid of homogeneity factor, Computers \& Fluids 77: 12-23.

https://doi.org/10.1016/j.compfluid.2013.02.013

Mobasheri, R.; Peng, Z.; Mirsalim, S. M. 2012. Analysis the effect of advanced injection strategies on engine performance and pollutant emissions in a heavy duty DI-diesel engine by CFD modeling, International Journal of Heat and Fluid Flow 33(1): 59-69. https://doi.org/10.1016/j.ijheatfluidflow.2011.10.004

Patankar, S. 1980. Numerical Heat Transfer and Fluid Flow. CRC press. $214 \mathrm{p}$.

Sands, P.; Peel, J.; Fabra, A.; MacKenzie, R. 2018. Principles of International Environmental Law. Cambridge University Press. 1032 p. https://doi.org/10.1017/9781108355728

Taghavifar, H.; Khalilarya, S.; Jafarmadar, S.; Baghery, F. 2016. 3-D numerical consideration of nozzle structure on combustion and emission characteristics of DI diesel injector, Applied Mathematical Modelling 40(19-20): 8630-8646.

https://doi.org/10.1016/j.apm.2016.05.010 